NBER WORKING PAPER SERIES

\title{
R\&D: A SMALL CONTRIBUTION TO PRODUCTIVITY GROWTH
}

\author{
Diego Comin \\ Working Paper 10625 \\ http://www.nber.org/papers/w10625 \\ NATIONAL BUREAU OF ECONOMIC RESEARCH \\ 1050 Massachusetts Avenue \\ Cambridge, MA 02138 \\ July 2004
}

I am grateful to Oded Galor (the Editor) and two anonymous referees, to Alberto Alesina, Jess Benhabib, Michelle Connolly, Xavier Gabaix, Peter Howitt, Chad Jones, Sam Kortum, Boyan Jovanovic, Sydney Ludvingson, Greg Mankiw, Pietro Peretto, Ned Nadiri, the seminar participants at Duke, Columbia, GSASStern macro lunch, NY-SED, NBER summer institute, Minnesota macro wokshop, and very specially to Robert Solow for comments, suggestions and long communications. Financial assistance from the C.V. Starr Center is gratefully acknowledged. Please direct correspondence to diego.comin@nyu.edu. The views expressed herein are those of the author(s) and not necessarily those of the National Bureau of Economic Research.

(C)2004 by Diego Comin. All rights reserved. Short sections of text, not to exceed two paragraphs, may be quoted without explicit permission provided that full credit, including (C) notice, is given to the source. 
R\&D: A Small Contribution to Productivity Growth

Diego Comin

NBER Working Paper No. 10625

July 2004

JEL No. O40, E10

\section{$\underline{\text { ABSTRACT }}$}

In this paper I evaluate the contribution of $R \& D$ investments to productivity growth. The basis for the analysis are the free entry condition and the fact that most R\&D innovations are embodied. Free entry yields a relationship between the resources devoted to R\&D and the growth rate of technology. Since innovators are small, this relationship is not directly affected by the size of R\&D externalities, or the presence of aggregate diminishing returns in $\mathrm{R} \& \mathrm{D}$ after controlling for the growth rate of output and the interest rate. The embodiment of R\&D-driven innovations bounds the size of the production externalities. The resulting contribution of $R \& D$ to productivity growth in the US is smaller than three to five tenths of one percentage point. This constitutes an upper bound for the case where innovators internalize the consequences of their R\&D investments on the cost of conducting future innovations. From a normative perspective, this analysis implies that, if the innovation technology takes the form assumed in the literature, the actual US R\&D intensity may be the socially optimal.

Diego Comin

Department of Economics

New York University

269 Mercer Street, 725

New York, NY 10003

and NBER

diego.comin@nyu.edu 


\section{Introduction}

In this paper, I try to answer two questions: First, what has the contribution of R\&D to productivity growth been in the US during the post-war period? After providing an estimate for the R\&D contribution, I can answer the second: How does the actual R\&D intensity compare to the socially optimal intensity?

The first question has been examined repeatedly before by computing the social return to R\&D in a simple econometric framework. Typically, the endogenous variable is the Solow residual and the explanatory variables are the firm's or industry's own R\&D intensity and the used R\&D from other firms or industries. The estimated return to own R\&D ranges from .2 to .5, while for the used R\&D the estimate ranges from .4 to .8 with a total social return to R\&D of about 70 to 100 percent. ${ }^{1}$ These numbers are very large. Indeed, since the average share of non-defense R\&D in GDP over the postwar period has been 1.6 percent, they imply that the Solow residual is fully accounted by R\&D alone.

Before accepting this conclusion, we should keep in mind one important caveat to this econometric approach. Namely, that there are many factors omitted in the typical regression that affect simultaneously TFP growth and the parties incentives to invest in R\&D. The most obvious candidates are anything that enhances disembodied productivity, like the managerial and organizational practices, learning by doing,... All these elements have a clear effect on TFP and at the same time induce firms to invest in R\&D. Some evidence in favor of the potential importance of this bias comes from the fact that, after including fixed effects in the regression, the effect of R\&D on TFP growth almost disappears (Jones and Williams [1998]).

To overcome this omitted variable bias, I depart from the econometric framework. Instead, I use a model with endogenous development of new technologies to assess the importance of R\&D for growth. From a methodological point of view, I do not attempt to calibrate directly the social return to $\mathrm{R} \& \mathrm{D}$ in order to determine its role on growth. My route is more indirect since it decomposes the problem into two parts. First, I compute the effect of the amount of resources devoted to R\&D on the output of the $\mathrm{R} \& \mathrm{D}$ sector (that is the growth rate of $\mathrm{R} \& \mathrm{D}$ driven technologies). Then, I use simple growth accounting to compute the effect of the growth of technology on productivity growth.

One possible way to establish the first relationship ( i.e. between the resources devoted to R\&D

\footnotetext{
${ }^{1}$ See Griliches [1992], Jones and Williams [1998] and Nadiri [1992] for references.
} 
and the growth rate of technology) consists in calibrating the production function of technology. This approach, however, entails probably even more challenges than the traditional productivity approach because in addition to measuring the externalities involved in R\&D, we need to specify an R\&D production function. I discuss this further below in the context of a specific empirical test.

The approach I propose in this paper, instead, exploits the free entry condition into R\&D and the fact that R\&D innovations are embodied. Free entry implies that, in equilibrium, R\&D firms break even. As a result, the cost of the resources devoted to R\&D equals the value of the newly developed technologies. From here, it follows that the relationship between the share of resources devoted to R\&D and the growth rate of technology is a linear function of the inverse of the market value of an innovation.

The advantage of using a free entry condition instead of the production function for innovations is that it is very easy to compute the private vale of an innovation. Since innovators are small, they don't take into account the effect of their investment decisions on the aggregate variables when computing the value of an innovation. Therefore, I can redo the asset pricing calculations conducted by individual innovators where they take as given observable aggregate variables to calculate the private value of an innovation. Then, I can use the free entry condition to calibrate the growth rate of new technologies for a given $R \& D$ intensity without having to take any stand on the specification or calibration of the production function for new technologies.

To implement this exercise, I follow most of the productivity literature by using the NSF data on R\&D. The NSF measures the resources spent towards the development of new knowledge, products and processes by workers with training in physical sciences. It is important to understand that these innovations affect the production of final output mostly through the development of new goods. ${ }^{2}$ In that sense, the innovations that result from the R\&D activities, as measured by the NSF, represent by and large innovations that are embodied in the sense of Solow [1959]. This means that a firm can only benefit from R\&D by using the goods that result from the R\&D activities. ${ }^{3,4}$

\footnotetext{
${ }^{2}$ Process innovations can be thought as resulting in the development of new goods that replace the old ones. The model used in the next section to calibrate the R\&D contribution to productivity growth naturally accomodates this mechanism.

${ }^{3}$ Of course, R\&D labs could benefit from the knowledge created in previous R\&D efforts. These R\&D externalities are addressed below. I will not consider, however, the possibility that final output firms benefit from the knowledge created in the labs without using the goods that embody it.

${ }^{4}$ Clearly, there are other (non-RED) intentional investments that lead to improvements in productivity. These investments are mostly disembodied in the sense that, to enjoy the gains in productivity, firms do not need to adopt any new capital or intermediate good. A few examples in this category are: the resources Henry Ford devoted to
} 
The results I obtain are quite striking given the existing consensus about the importance of R\&D for growth. ${ }^{5}$ The average annual growth rate of productivity in the US during the post-war period has been 2.2 percentage points. Less than 3 to 5 tenths of 1 percentage point are due to R\&D.

The intuition for this small contribution is quite simple. The few resources devoted to R\&D signal a small private value of the innovations. But, as the bulk of the productivity literature has argued, there may be significant externalities that lead to large productivity gains even with few $R \& D$ investments. These externalities can appear in the production of final output or in the R\&D process.

Production externalities arise because the development of one innovation has an effect on labor productivity beyond its contribution to the capital stock (i.e. it affects the Solow residual). When innovations are embodied, firms enjoy production externalities to the extent that they use the new goods. Further, a larger production externality implies that, for a given number of available innovations, the demand faced by new innovators is higher. Therefore, ceteris paribus, the market value of an innovation is positively correlated with its social value. In terms of my two-step approach, this means that a larger production externality raises the effect of the growth of technology on productivity growth but reduces the growth of technology associated with a given R\&D intensity. As a result, the $R \& D$ contribution to productivity growth is not very sensitive to the size of the externalities in production.

$R \& D$ externalities associate past $R \& D$ investments with a reduction in the cost of developing future innovations. To show the inconsistency of large $R \& D$ externalities and a low $R \& D$ intensity in steady state, suppose for a moment that the $R \& D$ externalities were large and that the economy is in steady state. Then, a small R\&D intensity today, can generate a large growth rate of technology that in turn generates a large reduction in the costs of developing innovations tomorrow. As a result, tomorrow, agents want to devote a large share of resources into R\&D; but this is inconsistent with the fact that the share of resources devoted to $R \& D$ is constant in steady state. Therefore, the observed low $R \& D$ intensity indicates that $R \& D$ externalities cannot be very large.

The free entry condition establishes a relationship between the R\&D intensity and the growth improve the mass production system, McKinsey's reports, the resources devoted to develop better personnel and accounting practices, or any other managerial innovation.

${ }^{5}$ The only exception to this consensus is the BLS who reports a R\&D contribution to Total Factor Productivity growth of 0.2 percentage points. This difference steams from the rate of return for R\&D that the BLS imputes which is substantially lower than in the rest of the literature. 
rate of technology that can be used to calibrate the size of the $R \& D$ externalities. Once this is done, we can solve the social planner's problem. This entails determining how much she would invest in R\&D with the calibrated production structure. Then we can compare this socially optimal R\&D intensity with the actual intensity in order to answer the second question posed in this paper. Specifically, I find that the observed R\&D intensity may be quite close to the socially optimal intensity.

The rest of the paper is structured as follows. Section 2 contains the baseline calibration One clear goal of this paper is to show that the magnitude of the calibrated R\&D contribution to productivity growth is very robust. Section 3 tries to show this by considering more general production functions that accommodate more flexible relationships between R\&D-driven technology and productivity growth. This analysis emphasizes the importance that R\&D innovations are embodied. In this sense, this paper contributes to the literature started with Phelps [1962] on the relevance of the decomposition between embodied and disembodied technological progress. In section 3.1, I investigate some elements that affect the relationship between the share of resources devoted to R\&D and the growth rate of technology (for example the presence of increasing returns in the production of R\&D driven technologies, international spillovers, ...). In section 3.3, I move out of the steady state and consider how the calibrations would change had the US economy been in transition to the steady state. In section 4 , I discuss the limits of the approach proposed in this paper. Section 5 draws the welfare implications of the previous analysis. Section 6 concludes.

\section{The basic argument}

Throughout the paper I use $\dot{X}$ to designate the time derivative of a generic variable $X$, and $\gamma_{X}$ to denote the growth rate of variable $X$. Let's denote by $A$ the level of technology associated with R\&D investments. In the terminology of Romer [1990] or Grossman and Helpman [1991, ch. 3], this is the number of varieties though I will show later that this framework can accommodate other interpretations. To compute the R\&D contribution to productivity growth, I start by investigating the relationship between the amount of resources devoted to R\&D (expressed in units of final output, which is the numeraire), $R$, and the growth rate of technology. Then I use a production function to relate the growth rate of $A$ to the growth rate of labor productivity.

Let $P_{A}$ denote the market price of a firm that has earned a patent to produce one of these varieties. The free entry condition implies that innovators make zero profits in equilibrium, there- 
fore the cost incurred to develop the patent $(R)$ is equal to the market value of the flow of new technologies $\left(P_{A} \dot{A}\right){ }^{6}$

$$
P_{A} \dot{A}=R
$$

The free entry condition yields the following expression for the growth rate of R\&D-driven technologies

$$
\gamma_{A}=s \frac{Y}{P_{A} A},
$$

where $Y$ denotes the economy-wide output, $s$ denotes the share of resources devoted to R\&D (i.e. $\left.s \equiv \frac{R}{Y}\right)$. To establish the link between R\&D intensity $(s)$ and the growth rate of R\&D-driven technologies $\left(\gamma_{A}\right)$ we just need to find an expression for $\frac{Y}{P_{A} A}$. For that it is necessary to specify a production function and to price the stock of patents.

Final output $\left(Y_{t}\right)$ is produced out of labor $\left(L_{t}\right)$ and intermediate goods $\left(x_{i t}\right)$. In particular, I assume the functional form in equation (2)

$$
Y_{t}=Z_{t} L_{t}^{1-\alpha}\left(\sum_{i=1}^{A_{t}} x_{i t}^{\alpha \rho}\right)^{\frac{1}{\rho}}
$$

where $Z_{t}$ denotes the level of non-R\&D-driven technology. ${ }^{7}$

Standard profit maximization implies the following inverse demand curve for intermediate goods

$$
p_{i t}=\alpha L_{t}^{1-\alpha}\left(\sum_{i=1}^{A_{t}} x_{i t}^{\alpha \rho}\right)^{\frac{1}{\rho}-1} x_{i t}^{\alpha \rho-1}
$$

where $p_{i t}$ denotes the price of the $i^{t h}$ variety.

To produce one unit of intermediate goods producers need to use a unit of capital whose rental price is $r .{ }^{8}$ Innovators can charge a markup $(\eta)$ above the marginal cost of production either because they earn a patent or because they keep secret the blueprint of the innovation. Optimal pricing of the intermediate goods that embody the innovations implies that the markup is constant and

\footnotetext{
${ }^{6}$ For the argument to go through, we just need this relationship to hold in the long-run because our interest is on the determinants of long-run productivity growth.

${ }^{7}$ This specification introduces a wedge between the capital share $(\alpha)$ and the elasticity of substitution across different varieties which is equal to $\alpha \rho$.

${ }^{8}$ The calibrated effect of $\mathrm{R} \& \mathrm{D}$ on growth is independent of the rate of transformation between final output and intermediate goods. This parameter that here is normalized to 1 just cancels out.
} 
equal to the inverse of the elasticity of substitution between the different intermediate goods (i.e. $\left.\eta=(\alpha \rho)^{-1}\right)$.

After some algebra, it follows that the static operating profits earned by an innovator can be written as

$$
\pi=\frac{\eta-1}{\eta} \alpha \frac{Y}{A}
$$

From here, it follows that

$$
\frac{Y}{A}=\frac{\pi \eta}{\alpha(\eta-1)} .
$$

To close the first step in the argument, we just have to derive the market price of an innovation. Suppose for simplicity that patents do not expire and that innovators are not overtaken by new innovators with more sophisticated capital goods. Then the value of an innovation, $P_{A}$, must satisfy the following asset equation:

$$
r P_{A}=\pi+\dot{P}_{A}
$$

where $r$ is the relevant discount rate.

From equation (5) it follows that

$$
P_{A}=\frac{\pi}{r-\gamma_{P_{A}}}
$$

In steady state, all variables grow at constant rates. From equation (1), this implies that

$$
\gamma_{P_{A}}=\gamma_{Y}-\gamma_{A}
$$

Substituting expressions (4), (6) and (7) into equation (1) and isolating $\gamma_{A}$ we obtain the following expression for the growth rate of technology in terms of $s$ :

$$
\gamma_{A}=\frac{r-\gamma_{Y}}{\frac{\eta-1}{\eta} \frac{\alpha}{s}-1}
$$

There are two important observations from this expression. First, the link between $\gamma_{A}$ and $s$ does not come from a production function for technology; it follows from the positive relationship that the free entry condition (1) defines between the two. Second, $\gamma_{A}$ in expression (8) does not depend directly on the size of the externalities in R\&D or on the degree of the diminishing returns to aggregate R\&D investments; ${ }^{9}$ note that I have not even specified the production function for the

\footnotetext{
${ }^{9}$ In section 4.1.4 I generalize the analysis to allow for dynamic increasing returns in R\&D at the firm level by conceding incumbents a cost advantage in subsequent R\&D.
} 
creation of technologies. This is the case because we have mimicked the calculations made by small innovators that want to figure out the market price of their innovations $\left(P_{A}\right)$ and do not take into account the effect of their investment decisions on aggregate variables like the interest rate or the growth rate of output. Since the externalities appear through these aggregate variables, we do not need to calibrate them once we control for $\gamma_{Y}$ and $r$.

The second step in the computation of the R\&D contribution to productivity growth consists in using the production function (2) to relate the growth rate of R\&D driven technology $\left(\gamma_{A}\right)$ to the growth rate of productivity. From there it follows that

$$
\gamma_{Y / L} \equiv \gamma_{Y}-\gamma_{L}=\gamma_{Z}+\frac{1}{\rho} \gamma_{A}+\alpha\left(\gamma_{x}-\gamma_{L}\right)
$$

To solve for $\gamma_{x}$, I take advantage of the symmetry of the intermediate goods in production. From the pricing rule and the inverse demand function, it follows then that

$$
x_{i}=L\left(\alpha Z \frac{A^{\frac{1-\rho}{\rho}}}{\eta r}\right)^{\frac{1}{1-\alpha}} .
$$

In steady state $r$ is constant and therefore $\gamma_{x}-\gamma_{L}=\frac{1-\rho}{\rho(1-\alpha)} \gamma_{A}$. Plugging this back into (??), we obtain the following expression for the growth rate of productivity:

$$
\gamma_{Y / L}=\frac{1}{1-\alpha} \gamma_{Z}+\overbrace{\frac{1}{\rho}\left(\frac{1-\alpha \rho}{1-\alpha}\right) \gamma_{A}}^{\text {Contribution of R\&D to productivity growth }}
$$

Using the expression for the optimal markup and (8) we can rewrite the contribution of R\&D to productivity growth as follows:

$$
\text { Contribution of } \mathrm{R} \& \mathrm{D} \text { to productivity growth }=\frac{\alpha}{1-\alpha} \frac{r-\gamma_{Y}}{\left[\eta^{-1} \frac{\alpha}{s}-(\eta-1)^{-1}\right]}
$$

\subsection{Calibration}

To assess the role of $\mathrm{R} \& \mathrm{D}$ in productivity growth we must calibrate five parameters: $r, \gamma_{Y}, \alpha, s$ and $\eta$.

$s$ is calibrated using data from the National Science Foundation (NSF). The NSF estimates the expenditures from four surveys (Research and Development in Industry, Academic Research and Development Expenditures, Federal Funds for Research and Development, and Survey of R\&D Funding \& Performance by Nonprofit Organizations). Funds used for R\&D refer to current operating 
costs. These costs consist on both direct and indirect costs. They include not only salaries, but also fringe benefits, materials, supplies, and overhead. The R\&D costs also include the depreciation of the capital stock employed in R\&D activities.

To the extent that these surveys encompass only existing institutions, they will be ignoring current R\&D investments conducted by starting firms. For example, the NSF statistics ignore Bill Gates' time spent tinkering in his garage. The omission of these expenditures is probably not very relevant from a quantitative point of view. This claim follows from the fact that in 1999 only 4 percent of total industrial R\&D came from firms with less than 25 employees. This number is an upper bound for the average share of $R \& D$ from small firms for the post-War period since in 1998 it was only 3 percent and in 1997, the share of industrial R\&D from small firms was only 2 percent. Since most start ups become small incorporated firms and continue doing R\&D (surely more intensively than before incorporation), these small fractions should give us an idea of the small magnitude of the bias.

Figure 1 plots the evolution of the share of US non-defense R\&D expenditures in the US GDP as reported by the NSF. The average over the post-War period is about 1.6 percent. In my calibrations, I use a value for $s$ of 0.02 , which is an upper bound for the average share of resources devoted to non-defense R\&D during the post-war period in the US.

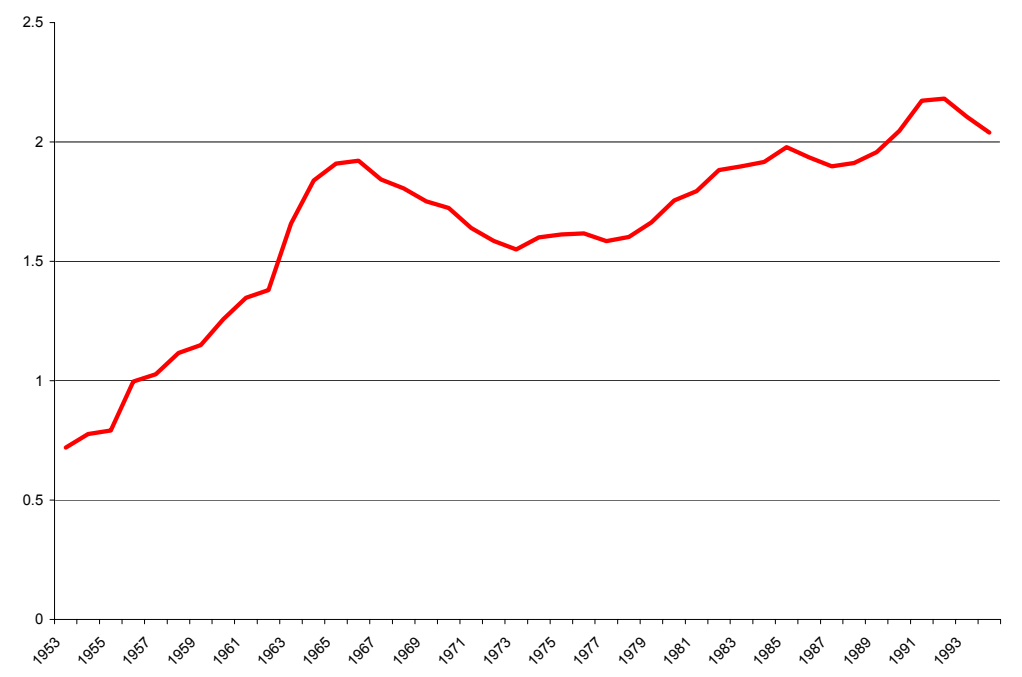

Figure 1: US share of non-defense R\&D expenditures in GDP in percentage points. Source: NSF.

$r$ is calibrated to the average real stock return in the US post-War period from Mehra and Prescott [1985]. Pakes and Schankerman [1984] provide evidence that this is approximately the private rate of return to $\mathrm{R} \& \mathrm{D}$ once we take into account the obsolescence of patents and the gestation lags that I incorporate in the next section. The average real growth rate of output $\left(\gamma_{Y}\right)$ 
between 1950 and 1999 in the US reported by the BLS is 0.034. $\alpha$ is calibrated to $1 / 3$ to match the capital share in the post-war period. For the markup $(\eta)$ I explore two values: 1.2 and 1.5. The latter is on the upper limit of the intervals given by Basu [1996] and Norrbin [1993] for the average markup in the economy. However, I regard this as more realistic since the markups charged by innovators should be well above the average markup in the economy because of the monopolistic power conferred by the patent system and because the higher ratio of the up front fixed cost to the marginal cost of production for technological goods than for non-technological goods or services. ${ }^{10}$

Table 1: Parameters

\begin{tabular}{cc}
\hline \hline$r$ & 0.07 \\
$\gamma_{Y}$ & 0.034 \\
$\alpha$ & 0.33 \\
$s$ & 0.02 \\
$\eta$ & $\{1.2,1.5\}$ \\
\hline \hline
\end{tabular}

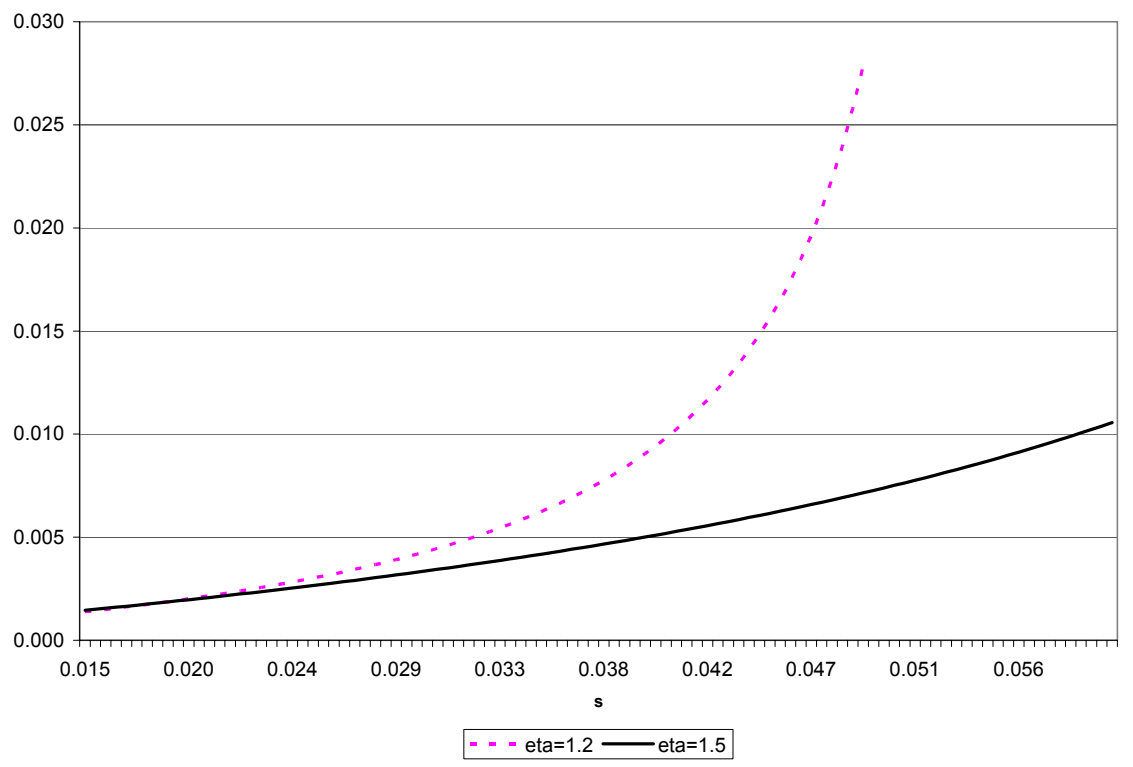

Figure 2: R\&D contribution to productivity growth in the baseline model.

Figure 2 displays the R\&D contribution to productivity growth for various levels of $R \& D$ intensity and for the two values of the markup. The first thing that stands out from this figure is that for R\&D intensities similar to the observed in the US post-war period (i.e. around 2 percent),

\footnotetext{
${ }^{10}$ Results hold a fortiori if $\eta$ is calibrated to a higher value.
} 
the $\mathrm{R} \& \mathrm{D}$ contribution to productivity represents only about a tenth of the average annual growth rate of productivity in the post-war period (2.2 percent). For the higher markup $(\eta=1.5)$ even an R\&D intensity three times larger than the observed in the US (6 percent) only would account for half of the growth rate of productivity observed in the post-war period. For the low (less realistic) markup $(\eta=1.2)$, an R\&D intensity of 4 percent is necessary to account for half of the post-war productivity growth rate. To account for all the post-war productivity growth the required R\&D intensities are 4.8 percent for the low markup case and 8 percent for the high markup.

In other calibrations not reported here, I have observed that the small $R \& D$ contribution to productivity growth is very robust to the parameterization of the interest rate $(r)$. This allows me to extend the results to environments where the opportunity cost of R\&D investments is higher because innovators are credit constrained or more risk averse.

The small contribution of $R \& D$ is the result of three effects. First, the low $R \& D$ intensity observed in steady state implies that the externalities in the R\&D process are small. Otherwise, future R\&D investments would be very profitable and we should observe a large R\&D intensity. Second, the small $\mathrm{R} \& \mathrm{D}$ intensity also implies that the growth rate of $A$ for any given markup (within reasonable bounds) must be relatively low. Finally, in this environment where R\&D innovations affect productivity through the goods that embody them, the contribution of production externalities to productivity growth is equal to $\left(\frac{1}{\rho}-\alpha\right) \gamma_{A}$. For given $\alpha$ and $\gamma_{A}$, a lower elasticity of substitution across the different intermediate goods increases the size of the production externalities. However, a reduction in the elasticity of substitution also raises the markup $(\eta)$. Naturally, this results in a higher $P_{A}$ and, from the free entry condition, in a lower $\gamma_{A}$ for any given R\&D intensity $(s)$. In other words, as I will emphasize in section 3.2, the embodiment assumption introduces a trade off between the growth rate of $\mathrm{R} \& \mathrm{D}$-driven technology and the size of the production externalities that bounds the R\&D contribution to productivity.

\section{Extensions}

Now, I extend the baseline model along several dimensions to show that the size of the R\&D contribution to productivity growth is robust. The first group of extensions deals with considerations that affect the private value of an innovation. These include the obsolescence of innovations, the presence of international spillovers in R\&D investments, R\&D lags, the imitation of innovations, and the possibility of successive R\&D for incumbent firms (i.e. firm-level increasing returns to R\&D). 
The second extension generalizes the production function to capture more general externalities in the production of final output. Finally, I relax the assumption that the economy is in steady state and compute the R\&D contribution to productivity growth if the US economy had been in transition during the post-war period.

\subsection{The value of innovations}

In the free entry condition, equation (1), we can see that the relationship between the share of resources devoted to R\&D and the growth rate of technology is mediated by the value of innovations. Therefore, in principle, the R\&D contribution to growth could be increased by enriching the model with new dimensions of the R\&D process that affect the value of innovations. Next, I show that the small contribution is robust to many variations.

\subsubsection{Creative destruction}

To incorporate the firm dynamics that characterize the Schumpeterian models of Aghion and Howitt [1992] and Grossman and Helpman [1991, chapter 4] I follow Jones and Williams [2000]. They introduce the concept of innovation clusters to capture the idea that innovations come in bunches and that firms must adopt all of the innovations in a cluster to actually benefit from it. Say, out of every $\left(\psi_{N}+\psi\right)$ intermediate goods developed, only $\psi_{N}$ are completely new. The rest are just new versions of existing intermediate goods that are necessary to use the new intermediate good. These new versions are otherwise identical to the existing ones. ${ }^{11}$ When a new cluster is adopted, the new versions of existing intermediate goods replace the old versions and this limits the expected life-time of an innovation.

When a new technological cluster is developed, the incumbents may try to prevent the diffusion of the new technological cluster by reducing their prices. This introduces some richer interactions in the pricing of intermediate goods. In particular, two scenarios are possible. It may be the case that these reactions do not constrain the pricing decisions of the innovators. Then the innovator charges the monopolist price, $p=r /(\alpha \rho)$. Alternatively, the limit pricing rule may be binding. Since in reality we observe that new products are developed and adopted I focus on the equilibrium where

\footnotetext{
${ }^{11} \mathrm{~A}$ simple example that illustrates this concept is a CD writer. Before the CD writer was developed, we just had a CD reader and a software for this to work. Now with the CD writer, we must modify the CD reader's software to make possible the interaction between the two drives. In this case, $\psi=1$ (the software) and $\psi_{N}=1$ (the CD writer).
} 
new intermediate goods are immediately adopted. ${ }^{12}$ After imposing this restriction we can derive the limit pricing rule that is consistent with the adoption of new varieties. Jones and Williams [2000], show that the markup under limit pricing is

$$
\eta^{L}=\left(\frac{\psi_{N}}{\psi}+1\right)^{\frac{1}{\alpha \rho}-1}
$$

Intuitively, the higher the ratio of the number of new goods to the number of complementary goods that must be changed to use the new innovation $\left(\frac{\psi_{N}}{\psi}\right)$, the lower is the limit markup because more incumbents are willing to reduce their prices to prevent adoption. Quite naturally, the limit price is also decreasing in the elasticity of substitution across intermediate goods. The resulting price for intermediate goods is $p_{i t}=\eta r_{t}$ where

$$
\eta=\min \{\overbrace{\frac{1}{\alpha \rho}}^{\text {monopolistic markup }}, \overbrace{\left(1+\frac{\psi_{N}}{\psi}\right)^{\frac{1}{\alpha \rho}-1}}^{\text {limit pricing markup }}\} .
$$

The new free entry condition is now

$$
P_{A} \frac{\psi_{N}+\psi}{\psi_{N}} \dot{A}=R
$$

The price of innovations must also satisfy the following asset equation:

$$
\overbrace{r P_{A}}^{\text {opportunity cost }}=\overbrace{\pi}^{\text {profit flow }}+\overbrace{\dot{P}_{A}-\frac{\psi}{\psi_{N}} \gamma_{A} P_{A}}^{\text {capital gain }}
$$

From here it follows that

$$
\gamma_{A}=\frac{r-\gamma_{Y}}{\left(\frac{\left(\frac{\eta-1}{\eta}\right) \alpha}{s}-1\right)\left(1+\frac{\psi}{\psi_{N}}\right)}
$$

and that the R\&D contribution of to productivity growth is

$$
\mathrm{R} \& \mathrm{D} \text { contribution to productivity }=\frac{1}{\rho}\left(\frac{1-\alpha \rho}{1-\alpha}\right) \gamma_{A} .
$$

\footnotetext{
${ }^{12}$ If this is not the case, there is no reason to undertake R\&D investments.
} 
I do not attempt to calibrate $\frac{\psi}{\psi_{N}} \cdot{ }^{13}$ As in the baseline model, $\rho$ is calibrated by exploiting its relationship with the markup. Now there are two cases depending on whether the innovator can charge the monopolistic markup or whether she is forced to use the limit pricing rule.

Case 1: If $\eta=\frac{1}{\alpha \rho}$ then $\frac{1}{\rho}=\eta \alpha$. Figure 3 plots the contribution of R\&D to productivity growth for different values of $\eta$ and $\frac{\psi}{\psi_{N}}$ for an R\&D intensity of 2 percent. In the figure we can see that under monopolistic pricing the contribution of R\&D to growth is bounded above by two tenths of one percentage point. That is, $R \& D$ cannot account for more than one tenth of the postwar productivity growth under monopolistic pricing of the innovations.

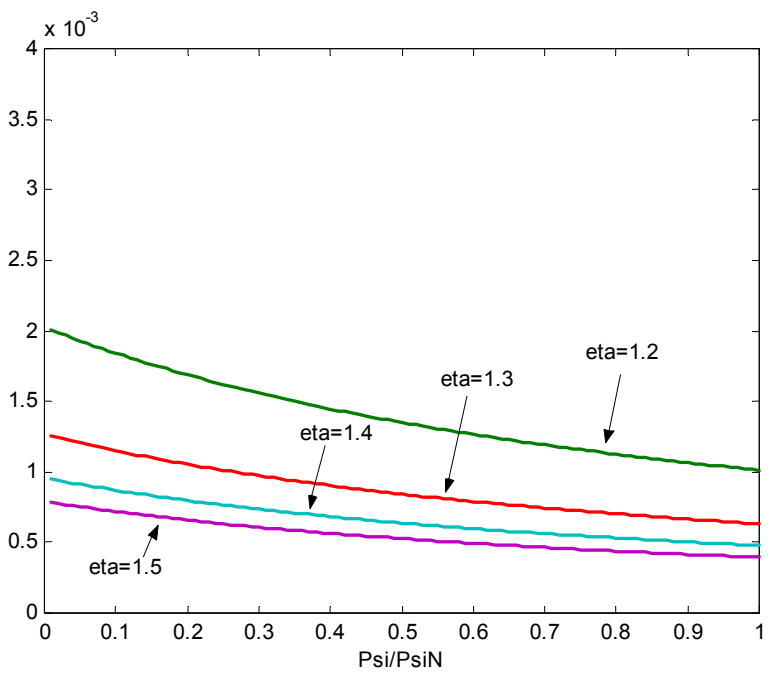

Figure 3: Contribution of R\&D to productivity growth, monopolistic pricing.

Case 2: If $\eta=\left(1+\frac{\psi_{N}}{\psi}\right)^{\frac{1}{\rho \alpha}-1}$ then

$$
\rho=\left[\alpha\left(1+\frac{\ln (\eta)}{\ln \left(1+\frac{\psi_{N}}{\psi}\right)}\right)\right]^{-1}
$$

\footnotetext{
${ }^{13}$ This could be done by using data on the average life span of a patent or, when more sophisticated concepts of firms are introduced, on the average life span of a firm or on the average number of patents held by an innovator.
} 


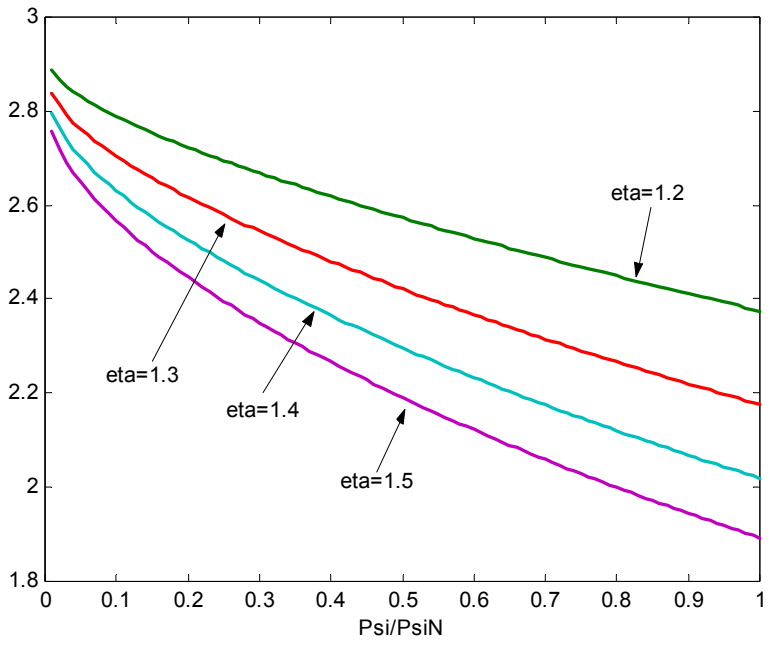

Figure 4: $\rho\left(\psi / \psi_{N} \mid \eta\right)$

Figure 4 plots the relationship between $\rho$ and $\psi / \psi_{N}$ implied by the limit pricing rule for several values of $\eta$. Figure 5 plots the contribution of R\&D to productivity growth as a function of $\psi / \psi_{N}$ under limit pricing for different markups for an R\&D intensity of 2 percent. In this case, the upper bound of the contribution of R\&D to productivity growth is one tenth of a percentage point.

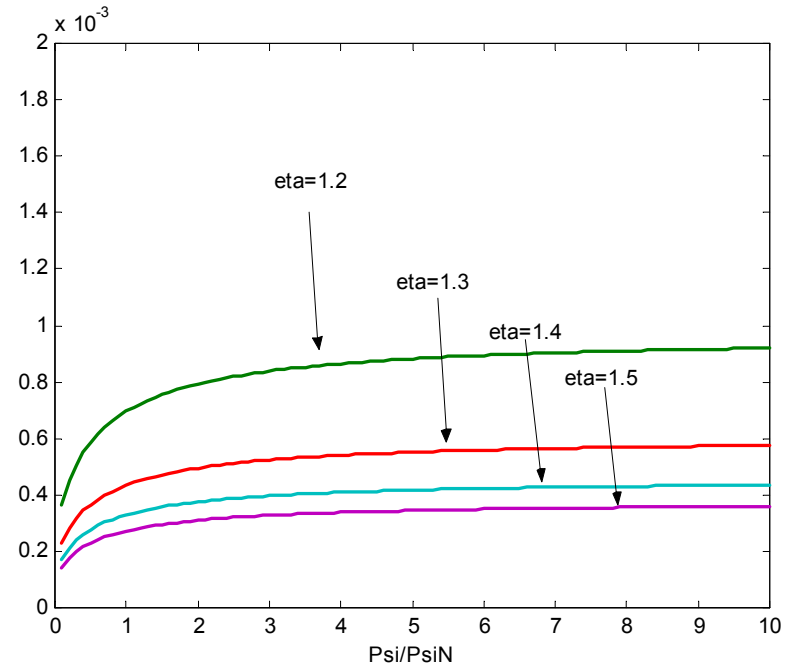

Figure 5: R\&D contribution to productivity growth under limit pricing.

An interesting observation that arises at this point, is that the effect of $\psi / \psi_{N}$ on the $\mathrm{R} \& \mathrm{D}$ contribution to productivity growth depends on the pricing rule. Under monopolistic pricing, the 
$\mathrm{R} \& \mathrm{D}$ contribution to productivity is decreasing in the ratio $\frac{\psi}{\psi_{N}}$ because the value of an innovation $\left(P_{A}\right)$ increases with the ratio ${ }^{14}$ and, from free entry, this reduces the growth rate of $A$ consistent with the observed R\&D intensity. When innovations' prices are limited by the prices of the previous innovations, the contribution is increasing in $\psi / \psi_{N}$ because, in addition to the previous effect, now $\rho$ decreases in $\psi / \psi_{N}$, for any given markup, as illustrated in figure 4 . As we have just argued, the size of the production externalities decreases with the elasticity of substitution across varieties, and therefore it increases in the ratio $\psi / \psi_{N}$. This effect dominates the effect on $P_{A}$ and, as a result, the R\&D contribution to productivity increases with $\psi / \psi_{N}$.

\subsubsection{Correlated shocks}

In the baseline model we have assumed that the obsolescence shocks are independent across the different intermediate goods in a common innovation cluster. This is probably not a very realistic assumption. When a new technological cluster is developed, there is a chance that it drives out of the market a large number of intermediate goods of an older cluster. In this scenario, the shocks faced by the intermediate goods in a given cluster are highly correlated. In Comin [2002] I model this idea in the simple case where each new technological cluster makes completely obsolete an older cluster. This is precisely the structure of the simple quality ladder models. It turns out from my analysis that even after introducing correlated shocks and R\&D lags, the contribution of R\&D to productivity growth for the more reasonable markups is bounded above by 3 to 5 tenths of one percentage point.

\subsubsection{Imitation}

Another relevant extension consists in relaxing the assumption of perfect enforcement of patents. If imitators are able to copy the goods developed by the innovators, the value of innovations declines and the free entry condition yields a higher growth rate of $A$ for any given R\&D intensity. Nevertheless, imitation does not affect substantially the R\&D contributions to productivity growth computed above. Mansfield el al. [1981] have information about the probability that an innovation is imitated and about the average cost of imitation. If in addition we recognize that imitations

\footnotetext{
${ }^{14}$ This follows because an innovator that has succeeded in developing a new technological cluster collects revenues from $\psi+\psi_{N}$ goods. At the same time, the probability that future researchers erode his rents in any of these goods is increasing in $\frac{\psi}{\psi_{N}}$. As in Schumpeterian growth models, the first effect dominates because it comes first in time and, as a result, $P_{A}$ increases with $\frac{\psi}{\psi_{N}}$.
} 
are not more valuable than the original innovations, then we can easily redo our calculations and observe that the R\&D contribution to productivity growth is bounded above by 3 to 5 tenths of one percentage points. ${ }^{15}$

\subsubsection{Subsequent $R \& D$ cost advantage}

Up to now, a firm has been characterized by the set of varieties that form an innovation cluster. All of these intermediate goods are developed simultaneously and once they become obsolete the firm vanishes. However, the evidence tells us that a large fraction of innovations are developed by firms that have already developed some other innovation clusters. This can be due to the fact that the costs of innovation decline with the number of varieties developed (i.e. there is some form of increasing returns to $R \& D$ at the firm level). If this is the case, innovations are more valuable than what we have computed so far. Investing in R\&D not only grants the right to future revenues from the new innovation cluster but also the option to develop more clusters in the future at a lower cost. To reconcile the higher value of innovations with the observed low $s$, the free entry condition now dictates a lower growth rate of varieties and a smaller contribution of R\&D to productivity growth.

This additional complexity is useful to generalize the argument made above to large firms. These internalize part of the positive consequences of their investment decisions. By taking advantage of part of the externalities, the value of the R\&D firm increases, and the growth rate of varieties induced by a given share of R\&D is lower than when firms are small. Hence, the benchmark contribution computed above gives an upper bound for the role of R\&D in productivity growth when firms are allowed to grow. The appendix shows this statements formally.

\subsubsection{R\&D lags}

In reality there is a lag between the outlay of the $R \& D$ investment and the beginning of the associated revenue stream. This lag corresponds both to the lag between project inception and conception (the gestation lag), and the time from project completion to commercial application (the application lag). Rapoport [1971] and Wagner [1968] have gathered data on lags for 52 technologies in various manufacturing sectors and have found that these lags range between 1.5 and 2.5 years.

\footnotetext{
${ }^{15}$ Probably, this upper bound overstates the contribution of R\&D because some of the imitation expenses are likely to be reported as research and development expenses in the NSF surveys. This would have the effect of reducing $s$ in our calculations, and from the free entry condition, would result in a lower $\gamma_{A}$ and in a lower contribution to productivity growth.
} 
In Comin [2002] I show that introducing these lags in the analysis has a very small effect on the previous calculations.

\subsubsection{International technology flows}

Intermediate goods flow internationally. The new technologies developed in Japan can be purchased in the US and used in the production of final output. This observation has two implications for the baseline analysis. On the one hand, I should use the R\&D investments conducted in the whole world, and not just in the US, to calibrate the R\&D intensity. On the other, a US innovator now can sell her innovation to the whole world, and therefore I should take into consideration the effect of this larger market size on the value of innovations. In terms of our calibration, the first effect implies that now the free entry condition is

$$
P_{A_{w}} \frac{\left(\psi+\psi_{N}\right)}{\psi_{N}} \dot{A}=R_{w}
$$

where $R_{w}$ represents the R\&D in the world. Following the same logic as above, $P_{A_{w}}$ can be expressed as:

$$
P_{A_{w}}=\frac{\psi_{N} s_{w}}{\left(\psi+\psi_{N}\right) \gamma_{A}} \frac{Y_{w}}{A}
$$

where $Y_{w}$ and $s_{w}$ denote respectively the world level of output and the share of R\&D in the world's output.

The second effect implies that the profits of a successful innovator are a function of the output of the countries where she can sell her innovations. Since innovations can be sold internationally, the new profit flow from a new variety is:

$$
\pi_{w}=\left(\frac{\eta-1}{\eta}\right) \alpha \frac{Y_{w}}{A}
$$

As before, the value of an innovation is determined in the market and must satisfy an asset equation.

$$
r=\frac{\pi_{w}}{P_{A_{w}}}+\gamma_{P_{A_{w}}}-\frac{\psi}{\psi_{N}} \gamma_{A}
$$

The last term on the right hand side is the same as in the closed economy case. In steady state, equation (15) implies that $\gamma_{P_{A w}}$ is equal to $\gamma_{Y_{w}}-\gamma_{A}$. But the interesting action takes place in the profit rate. There we can see that the two consequences from the internationalization of the 
economy exactly cancel out. More specifically,

$$
\frac{\pi_{w}}{P_{A_{w}}}=\frac{\left(\frac{\eta-1}{\eta}\right) \alpha\left(\psi_{N}+\psi\right)}{s_{w} \psi_{N}} \gamma_{A}
$$

Intuitively, the international flow of intermediate goods raises the resources devoted to develop the varieties that are ultimately used in the production of US output. The flip side of the coin is that US' (and any other country's) innovators can sell their goods to a larger market. Since both forces are proportional to $Y_{w}$, they cancel out. ${ }^{16}$

Plugging this expression into the asset equation (16), we obtain the following growth rate of innovations:

$$
\gamma_{A}=\frac{r-\gamma_{Y w}}{\left(\frac{\left(\frac{\eta-1}{\eta}\right) \alpha}{s_{w}}-1\right)\left(1+\frac{\psi}{\psi_{N}}\right)}
$$

It is easy to see that the figures obtained cannot be larger than the ones obtained in the previous section. Note from expression (17) that $\gamma_{A}$ is increasing in $s_{w}$ and decreasing in $\gamma_{Y_{w}}$. In the postWar period, the growth rate of output in the OECD has been higher than in the US, and the share of R\&D in GDP is higher in the US than in the OECD. Therefore, the upper bounds for the R\&D contribution to productivity growth are unaffected by introducing international considerations. Since we have not specified a production function for new technologies, this conclusion holds for production functions that capture all sorts of international spillovers in R\&D.

\subsection{More general production functions ${ }^{17}$}

In the baseline model, the elasticity of productivity growth with respect to $\gamma_{A}$ is equal to $\frac{1-\alpha \rho}{\rho}+$ $\frac{\alpha(1-\alpha \rho)}{\rho(1-\alpha)}$, where the first term corresponds to the static externality of $A$ on output and the second to the capital deepening driven by the development of new technologies. One might argue that with a more general production function we could parameterize the externality in production in such

\footnotetext{
${ }^{16}$ This is not the case if international partners engage in R\&D but the US innovators cannot export their products. This scenario, however, seems empirically irrelevant.

${ }^{17}$ In this analysis I have assumed that the production function of final output is Cobb-Douglas. Basu [1997], Burnside, Eichembaum and Rebelo [1995] and Berndt [1976] among others have shown that a Cobb-Douglas is a good approximation to the US data. Further, in the working paper version of this article (Comin[2002]) I show that the growth rate of $R \& D$ innovations is not very sensitive to the elasticity of substitution between capital and labor.
} 
a way that $R \& D$ generates an arbitrarily large growth rate of productivity. One such production function would be

$$
Y=A^{\sigma} Z\left[\int_{0}^{A} x_{i}^{\alpha \rho}\right]^{\frac{1}{\rho}} .
$$

In this production function, by increasing $\sigma$ we can increase the size of the production externality and the R\&D contribution to growth. However, note also that in this production function R\&D innovations are not embodied. Firms do not need to buy a single unit of the latest innovation to benefit from the productivity gains associated with this innovation. But this is not consistent with the NSF definition of R\&D.

In what follows, I show that if $R \& D$ technologies are embodied the R\&D contribution to productivity does not depend very much on the size of the production externalities. Intuitively, the variable production externality introduces a wedge between the effective level of R\&D-driven technology and $A$. The embodied nature of $\mathrm{R} \& \mathrm{D}$ innovations implies that to benefit from them, firms must purchase the goods that embody these innovations. If the elasticity of the effective level of R\&D technology with respect to $A$ is larger than one, the efficiency of an innovation grows with its vintage. Moreover, a larger production externality generates a higher effective level of technology embodied in a new good, for a given $A$, and this, in turn, induces a larger demand and a higher value for the innovations. Hence, when $R \& D$ innovations are embodied, the free entry condition implies that a higher production externality reduces the growth rate of $A$ associated with a given R\&D intensity. This effect introduces a trade off that limits how much productivity growth can be explained by increasing the size of the production externalities.

To see this more formally, consider an environment that is exactly the same as in the baseline model but with the following aggregate production function:

$$
Y=Z L^{1-\alpha}\left[\int_{0}^{A} a_{i} x_{i}^{\alpha \rho} d i\right]^{\frac{1}{\rho}}
$$

where now the level of R\&D-driven technology is a continuous variable and the capital varieties have different efficiencies $a_{i}$. To introduce some flexibility on the size of the production externality, I set $a_{i}=b i^{\sigma-1}$, where $b$ is any positive constant that, without loss of generality, I normalize to 1 , $\sigma>\alpha \rho$ and $i$ is a technology index. The size of the externality in production is increasing in $\sigma$. When $\sigma>1$, newer innovations are more efficient than older innovations. 
The inverse demand for a particular variety $i$, is

$$
p_{i}=Z \alpha L^{1-\alpha}\left(\int_{0}^{A} a_{i} x_{i}^{\alpha \rho} d i\right)^{\frac{1}{\rho}-1} a_{i} x_{i}^{\alpha \rho-1} .
$$

Due to the isoelastic nature of the demand, innovators set a price equal to a constant markup $\eta$ times the marginal cost of production $r$. Following the same algebraic steps as in the standard model, we can easily find that when the state of the art technology has index $A$, the level of output is given by expression (18) and the profits for an innovator that developed a variety with index $i \leq A$ are given by (19)..$^{18}$

$$
\begin{aligned}
Y & =L Z^{\frac{1}{1-\alpha}} \alpha^{\frac{\alpha}{1-\alpha}}(\eta r)^{\frac{-\alpha}{1-\alpha}} A^{\frac{\sigma-\alpha \rho}{\rho(1-\alpha)}} \\
\pi_{i A} & =\frac{\eta-1}{\eta} \alpha \underbrace{\frac{\sigma-\alpha \rho}{1-\alpha \rho}}_{\text {Level effect }} \frac{Y}{A} \underbrace{\left(\frac{i}{A}\right)^{\frac{\sigma-1}{1-\alpha \rho}}}_{\text {Gradual substitution }}
\end{aligned}
$$

In this last expression, we can distinguish two effects of $\sigma$ on the profits of an innovator. The higher curvature in the efficiency of capital vintages $(\sigma)$, the higher the initial level of profits, but also the faster final good producers gradually substitute towards the new, more efficient, varieties.

Expression (19) can be rewritten in terms of the vintage of the variety sold by the innovator. More specifically, let $v_{i}$ be the vintage of the $i^{\text {th }}$ variety. In steady state, $A$ grows at the constant rate $\gamma_{A}$. Let's suppose that the economy started on the balanced growth path. Then the profits at time $t$ of an innovator that developed a vintage $v_{i}$ variety are:

$$
\pi_{v_{i} t}=\frac{\eta-1}{\eta} \alpha \frac{Y}{A} \frac{\sigma-\alpha \rho}{1-\alpha \rho} e^{-\left(\frac{\sigma-1}{1-\alpha \rho}\right)\left(t-v_{i}\right) \gamma_{A}} .
$$

When $\sigma>1$, the innovations embodied in newer varieties are more profitable than those embodied in older vintages. The converse is true when $\sigma<1$. Consequently, the market value of an innovation generically varies in the cross-section. Let $P_{A t, v}$ denote the price at time $t$ of a vintage $v$ innovation. From free entry, we know that

$$
P_{A t t}=\frac{s \psi_{N}}{\gamma_{A}\left(\psi_{N}+\psi\right)} \frac{Y}{A}
$$

\footnotetext{
${ }^{18}$ It can also be shown that

$$
K=\int_{0}^{A} a_{i} x_{i} d i=\chi_{K} Z^{\frac{1}{1-\alpha}} L A^{\frac{(\sigma-\alpha \rho)(1-\rho)+\rho(1-\alpha)(2 \sigma-1-\sigma \alpha \rho)}{\rho(1-\alpha)(1-\alpha \rho)}}
$$
}

where $\chi_{K}$ is a positive constant; and that

$$
Y=\chi_{Y} Z A^{\tilde{\sigma}} K^{\alpha} L^{1-\alpha},
$$

where $\chi_{Y}$ is another positive constant and $\tilde{\sigma}=\frac{\sigma(1-\alpha \rho)}{\rho}$. 
Since $P_{A t v}$ is determined in the market, it satisfies the following differential equation:

$$
r P_{A t v}=\pi_{v t}+\dot{P}_{A t v}-\frac{\psi}{\psi_{N}} \gamma_{A}
$$

It is easy to see that $P_{A t v}=P_{A t t} e^{-\gamma_{A}\left(\frac{\sigma-1}{1-\alpha \rho}\right)(t-v)} \cdot{ }^{19}$ This implies that $\gamma_{P_{A t v}}=\gamma_{Y}-\gamma_{A}\left(\frac{\sigma-\alpha \rho}{1-\alpha \rho}\right)$. Dividing both sides of equation (22) by $P_{A v t}$ and plugging (20) and this expression for $\gamma_{P_{A t v}}$, we can derive expression (23).

$$
\gamma_{A}=\frac{r-\gamma_{Y}}{\left(\frac{\left(\frac{\eta-1}{\eta}\right) \alpha}{s}\left(1+\frac{\psi}{\psi_{N}}\right)-1\right)\left(\frac{\sigma-\alpha \rho}{1-\alpha \rho}\right)-\frac{\psi}{\psi_{N}}}
$$

This expression differs from the growth rate of technology in the baseline model (??) in two respects. First, the profit rate of innovations increases with $\sigma$. Second, a higher $\sigma$ implies a higher expected capital loss due to the depreciation of the market value of the innovations. The first effect raises the current value of an innovation while the second reduces it. However, in expression (23) it is clear that the first force dominates the second, and the higher is the externality in production $(\sigma)$ the lower is the growth rate of technology associated with a given R\&D intensity.

To complete the calculation we just need to derive the growth rate of productivity from expression (18).

$$
\gamma_{Y / L}=\frac{1}{1-\alpha} \gamma_{Z}+\frac{\sigma-\alpha \rho}{\rho(1-\alpha)} \gamma_{A}
$$

Note that, for a given $\gamma_{A}$, the R\&D contribution to productivity growth is increasing in $\sigma$. However, doing some simple algebra we can check that, after taking into account the effect of $\sigma$ on $\gamma_{A}$, the $\mathrm{R} \& \mathrm{D}$ contribution to productivity growth is decreasing in $\sigma$. To assess the quantitative importance of these effects, I plot in figure 6 the R\&D contribution for several values of $\sigma$ and $\psi / \psi_{N}$ when the markup is equal to 1.2 and the R\&D intensity is 2 percent. ${ }^{20}$ For conciseness, I restrict myself to the case of monopolistic markups (i.e. $\eta=(\alpha \rho)^{-1}$ ).

\footnotetext{
${ }^{19}$ For this one can solve the differential equation (22) plugging in (20) and using the initial condition (21).

${ }^{20}$ For higher values of the markups the contribution is smaller.
} 


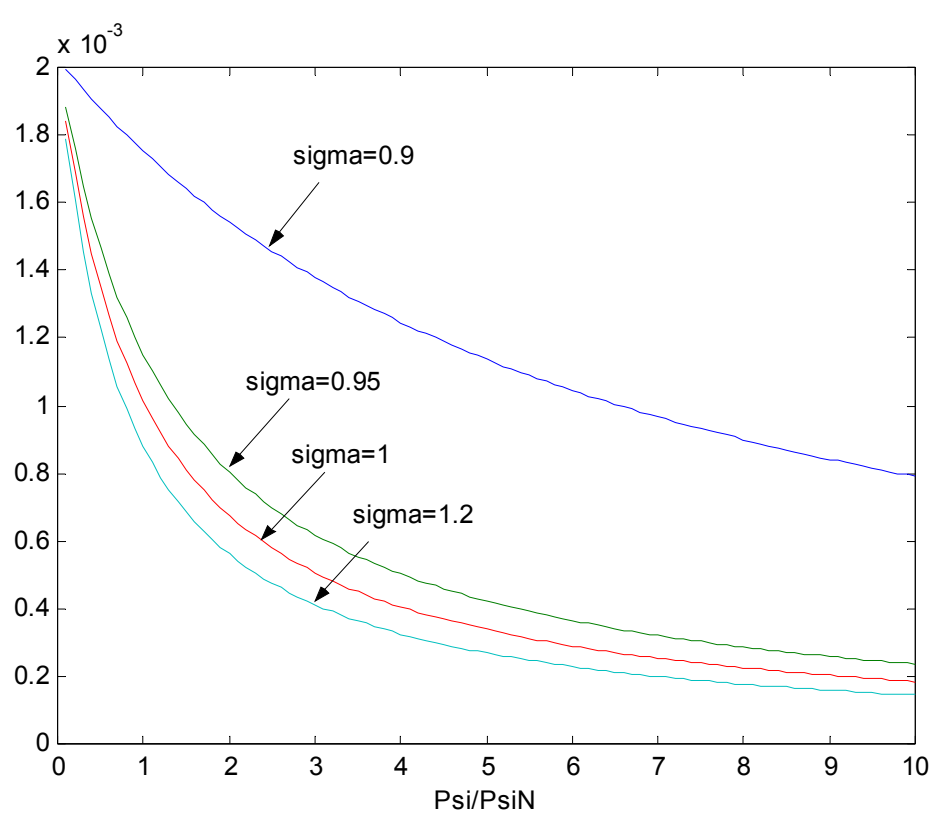

Figure 6: R\&D contribution to productivity growth with $\eta=1.2, s=0.02$, for several $\sigma^{\prime} s$

From this figure, we can see that, if $R \& D$ innovations are embodied, the $R \& D$ contribution to productivity growth is quite robust to the size of the production externality and it is smaller than two tenths of one percentage point.

This result relates this paper to a literature that has studied the relevance of the distinction between embodied and disembodied productivity growth. The interest in this question started with Phelps [1962] who showed that the elasticity of the steady state level of output with respect to the savings rate does not depend on the composition of technological progress. ${ }^{21}$ On the empirical front, Denison [1964] argued that embodied technological change represents a small fraction of productivity growth. Twenty years later, Mc Hugh and Lane [1987] came out with better estimates that controlled for the cyclical variation in the utilization of capital of different vintages and showed that the contribution of the embodied component of productivity growth was substantial. The argument presented in this section has brought the embodiment hypothesis to the core of the analysis. In line with the replies to Phelps [1962], it has show that the fact that R\&D innovations are embodied in new goods is very relevant to calibrate the contribution to labor productivity of R\&D investments.

\footnotetext{
${ }^{21}$ For the debate that followed see also Matthews [1964], Phelps and Yaari [1964], Levhari and Sheshinski [1967] and Fisher, Levhari and Sheshinski [1969].
} 


\subsection{Transition}

Jones [2001] has argued that the US economy has been in a transition to the steady state during the post-war period. In this section I study what the previous analysis implies if the US economy is in transition.

When deriving the relationship between $s$ and $\gamma_{A}$, I have assumed that the economy is in steady state only to compute the price appreciation of the innovations. Remember that free entry implies that

$$
P_{A}=\frac{s \psi_{N}}{\gamma_{A}\left(\psi_{N}+\psi\right)} \frac{Y}{A}
$$

If the economy is in the transition, then

$$
\gamma_{P_{A}}=\overbrace{\gamma_{Y}-\gamma_{A}}^{\text {Steady State }}+\overbrace{\gamma_{s}-\gamma_{\gamma_{A}}}^{\text {Transition }} \text {. }
$$

The asset pricing equation holds at every instant, but now we have to recognize the new expression for the price appreciation of an innovation. This yields the following differential equation for $\gamma_{A}$ :

$$
\frac{d\left(\ln \left(\gamma_{A}\right)\right)}{d t}-\left[\frac{\eta-1}{\eta} \frac{\alpha\left(\psi_{N}+\psi\right)}{s \psi_{N}}-\left(1+\frac{\psi}{\psi_{N}}\right)\right] \gamma_{A}=-\left(r-\gamma_{Y}-\gamma_{s}\right)
$$

Since $s$ is time varying this differential equation does not have a closed form solution. To approximate the average growth rate of $A$, we can solve this differential equation calibrating $s$ to the average $\mathrm{R} \& \mathrm{D}$ intensity during the transition. Then, the solution to this equation takes the form

$\gamma_{A}(t)=\left[C_{1} e^{e_{0}^{t}\left(r(v)-\gamma_{Y}(v)-\gamma_{s}(v)\right) d v}-\left[\frac{\eta-1}{\eta} \frac{\alpha\left(\psi_{N}+\psi\right)}{s \psi_{N}}-\left(1+\frac{\psi}{\psi_{N}}\right)\right] \int_{0}^{t} e^{\int_{v}^{t}\left(r(\tau)-\gamma_{Y}(\tau)-\gamma_{s}(\tau)\right) d \tau} d \tau\right]^{-1}$

For illustrative purposes, suppose that the term $\left(r(v)-\gamma_{Y}(v)-\gamma_{s}(v)\right)$ is constant. Then this expression is equal to

$$
\gamma_{A}(t)=\left[\tilde{C} e^{\left(r-\gamma_{Y}-\gamma_{s}\right) t}+\frac{\left[\frac{\eta-1}{\eta} \frac{\alpha\left(\psi_{N}+\psi\right)}{s \psi_{N}}-\left(1+\frac{\psi}{\psi_{N}}\right)\right]}{\left(r-\gamma_{Y}-\gamma_{s}\right)}\right]^{-1}
$$

In the long run $\left(r-\gamma_{Y}-\gamma_{s}\right)>0$, therefore for a steady state to exist, it is necessary that $\tilde{C}=0$. This implies that

$$
\gamma_{A}=\frac{r-\gamma_{Y}-\gamma_{s}}{\left[\frac{\eta-1}{\eta} \frac{\alpha\left(\psi_{N}+\psi\right)}{s \psi_{N}}-\left(1+\frac{\psi}{\psi_{N}}\right)\right]} .
$$


In figure 1, we can observe an upward trend in $s$ for the post-war period. This positive growth in $s$, yields a lower $\gamma_{A}$ in expression (25) and a lower R\&D contribution than if $s$ had remained constant. Intuitively, a (temporary) upward trend in the share of resources devoted to R\&D is due to an expected appreciation in the value of innovations. Therefore the current market price of innovations is higher and, from free entry, the associated growth rate of R\&D driven-technology must be lower.

\section{Discussion}

So far, I have argued that by exploiting the free entry condition we can assess the importance of R\&D for productivity growth. Specifically, if the markups charged by the innovators are large, if innovations are embodied in new intermediate goods and if the equilibrium R\&D intensity is small the contribution of $R \& D$ to productivity growth is quite small (i.e. about one tenth of the observed growth rate).

The analysis in section 3.2 has illustrated how the embodiment of innovations is an important element in this argument because it limits the size of the production externalities. This assumption seems very plausible in the light of what the NSF defines as R\&D. ${ }^{22}$ According to the NSF, "R\&D consists on activities carried on by persons trained, either formally or by experience, in the physical sciences such as chemistry and physics, the biological sciences such as medicine, and engineering and computer science. R\&D includes these activities if the purpose is to do one or more of the following things:

1. Pursue a planned search for new knowledge [...]. (Basic research)

2. Apply existing knowledge to problems involved in the creation of a new product or process [...]. (Applied research)

3. Apply existing knowledge to problems involved in the improvement of a present product or process. (Development)."

From this definition, it follows that the final product of the R\&D investments are new final, intermediate or capital goods and the effect of R\&D on productivity is embodied in these new goods in the sense of Solow [1959].

The NSF also presents a list of activities that must be excluded from the definition of R\&D. Among these we find social science expenditures, defined as those "devoted to further understand-

\footnotetext{
${ }^{22}$ In addition more than 75 percent of $R \& D$ is localized in the manufacturing sectors according to the NSF.
} 
ing [of] the behavior of groups of human beings or of individuals as members of groups [in the following areas]: personnel, economics, artificial intelligence and expert systems, consumer, market and opinion, engineering psychology, management and organization, actuarial and demographic...".

These intentional non-RED innovations also may lead to substantial improvements in productivity but are left out of this paper's analysis. ${ }^{23}$ One fundamental difference with the NSF notion of $\mathrm{R} \& \mathrm{D}$ is that these innovations are disembodied in the sense that, to enjoy the gains in productivity, firms do not need to adopt any new capital or intermediate good. This distinction is substantive because the degree of embodiment affects the specific mechanisms that prevent the imitation of the innovation and also the size of the externalities in production.

The validity of a calibration exercise always depends on how sensible the assumptions that underlay the model are. In addition to the assumptions just stated, there are other, more standard that also condition the analysis. ${ }^{24}$ In particular, throughout I have assumed that agents are rational and forward-looking in the evaluation of the costs and benefits from R\&D. Though I personally believe in this assumption, it may be argued that managers are myopic agents that engage in R\&D activities as a form of entry deterrence. In that case, the private value of R\&D may not be accurately captured by the asset equation I use and the whole approach may be compromised. Note however, that the fact that managers assign an extra value to R\&D because of strategic motives should in principle enhance the private value of innovations and from the free-entry condition the R\&D contribution to productivity growth should, ceteris paribus, be even smaller than figures given in this paper.

Having said that, I do regard the approach proposed here as a complement (rather than a substitute) to the more traditional econometric approach. Of course, the econometric approach encounters its own problems. In particular it is hard to overcome biases that arise from omitting relevant variables in the regression such as determinants or measures of disembodied productivity may vary over time and across firms.

In a recent paper, Jones [2002] also analyzes the sources of growth in the US post-war experience by posing a production function for new technologies that he estimates to determine how much growth can be attributed to R\&D. As Jones points out, the estimation of the production function for new technologies creates as many difficulties as the regressions in the productivity literature.

\footnotetext{
${ }^{23}$ Another mechanism that has been related to long-run growth and that is left out of this analysis is learning-bydoing. This however is not usually thought of as an intentional investment.

${ }^{24}$ In general, by imposing the free entry condition, I have to minimize the number of assumptions. For example, I have restricted the analysis at all with respect to the heterogenity of firms costs when conducting R\&D.
} 
In particular, the estimate of the elasticity of TFP growth with respect to $R \& D$ investments is likely to be biased for at least two reasons. First, business cycle fluctuations in R\&D expenditures imply that the regressor is endogenous. Second, the measurement error in $A$ (and the potential misspecification of the $R \& D$ production equation) also generate a correlation between the error term and the regressor. However, Jones appeals to the possible cointegration between $\log (\mathrm{R} \& \mathrm{D})$ and $\log (\mathrm{TFP})$ which imply that the OLS estimate of the elasticity is superconsistent (Hamilton $[1994]) .^{25}$

An important practical issue is whether this asymptotic result can be invoked in a finite sample application like Jones's. Campbell and Perron [1991] study this question using Monte Carlo analysis and conclude that a useful rule of thumb is that asymptotic results can be exploited in samples of the size encountered in empirical applications when we can reject the null of no cointegration using the asymptotic critical values. Using an augmented Dickey-Fuller test, I show in Comin [2002] that we cannot reject the null that there is no cointegration between $\log (\mathrm{R} \& \mathrm{D})$ and $\log (\mathrm{TFP})$. While this statistical tests does not altogether rule out the possibility that R\&D and TFP share a common trend, they do suggest that it may be difficult to exploit the asymptotic properties of cointegration systems in samples of the size we currently have in order to calibrate elasticity of TFP with respect to R\&D, and that exploring alternative approaches may be useful. This paper has presented one such alternative which implies a value of this elasticity than the typical calibration in Jones [2002].

\section{Welfare}

So far I have conducted a positive analysis of the contribution of R\&D to productivity growth. However, the previous findings can be used to conduct a normative analysis. In particular, we can proceed in the following three steps. First, specify a production function for innovations; second, use the computed growth rate of R\&D-driven technology $\left(\gamma_{A}\right)$ to quantify the size of externalities in the production of new technologies. Finally, solve the social planner's problem and determine the socially optimal R\&D intensity $\left(s^{*}\right)$.

Note that in contrast to the positive analysis, now it is necessary to specify a production function for new technologies, therefore our results will depend on the particular functional form specified. In this sense, this section just intends to compare our approach to previous ones. To this end, we

\footnotetext{
${ }^{25}$ Specifically, the measure of R\&D used by Jones [2002] and Comin [2002] is the number of workers in the R\&D sector.
} 
adopt the R\&D technology used by Jones and Williams [2000] which generalizes the innovation technology posed in Stokey [1995]. Specifically, they assume that

$$
\dot{A}_{t}=\delta \frac{1}{1+\psi / \psi_{N}} R_{t}^{\lambda} A_{t}^{\phi}
$$

where both $\lambda$ and $\phi$ are bounded above by 1 . In steady state, $\gamma_{A}$ is constant, therefore

$$
\frac{\gamma_{A}}{\gamma_{Y}}=\frac{\lambda}{1-\phi}
$$

Expression (27) relates the size of the R\&D externalities to the actual growth rate of the US economy and to the growth rate of $\mathrm{R} \& \mathrm{D}$-driven technology that I have already quantified in section 3.1 .

Following Jones and Williams [2000], I consider a production function for final output that displays static externalities. As in section 3.2, I relate the size of this externality to the elasticity of substitution across different varieties and to the importance of embodied productivity growth. In particular, output is produced according to expression (28).

$$
Y_{t}=A_{t}^{\tilde{\sigma}} Z_{t} K_{t}^{\alpha} L_{t}^{1-\alpha}
$$

From section 3.2, we know that, in this context, the growth rate of R\&D technology $\left(\gamma_{A}\right)$ is given by expression $(29)$ where $\sigma \equiv \rho \tilde{\sigma} /(1-\alpha \rho)$.

$$
\gamma_{A}=\frac{r-\gamma_{Y}}{\left(\frac{\left(\frac{\eta-1}{\eta}\right) \alpha}{s}\left(1+\frac{\psi}{\psi_{N}}\right)-1\right)\left(\frac{\sigma-\alpha \rho}{1-\alpha \rho}\right)-\frac{\psi}{\psi_{N}}}
$$

Expressions (27) and (29) define a relationship between $\lambda$ and $\phi$ for given $\left(\eta, \alpha, s, r, \gamma_{Y}, \psi / \psi_{N}\right.$, $\rho, \sigma)$, where these parameters can be calibrated in the decentralized economy. Table 3 summarizes this calibration.

Table 3: Parameters

\begin{tabular}{cc}
\hline \hline$r$ & 0.07 \\
$\gamma_{Y}$ & 0.034 \\
$\alpha$ & 0.33 \\
$s$ & 0.02 \\
$\psi / \psi_{N}$ & 0.25 \\
$\rho$ & $1 /(\eta \alpha)$ \\
$\sigma$ & $\{0.9,0.95,1,1.05\}$
\end{tabular}




\begin{tabular}{ll}
$\eta$ & 1.2 \\
\hline \hline
\end{tabular}

There are a few remarks worth making about this calibration. First, note that the markup $\eta$ is calibrated conservatively, and that I impose monopolistic pricing of the innovations in order to calibrate the elasticity of substitution across different varieties. Finally, note that in each technological cluster there are four times as many completely new goods as new versions of old goods.

Figure 7 plots the size of the R\&D externality $(\phi)$ associated with various levels of the static externality $(\sigma)$ and with the size of the stepping on the toes effect $(1-\lambda)$. This relationship is quite robust to the variation of the rest of the parameters and in this benchmark I have chosen values of $\eta, \rho, \psi / \psi_{N}$ and $\theta$ that yield a higher schedule for $\phi$.

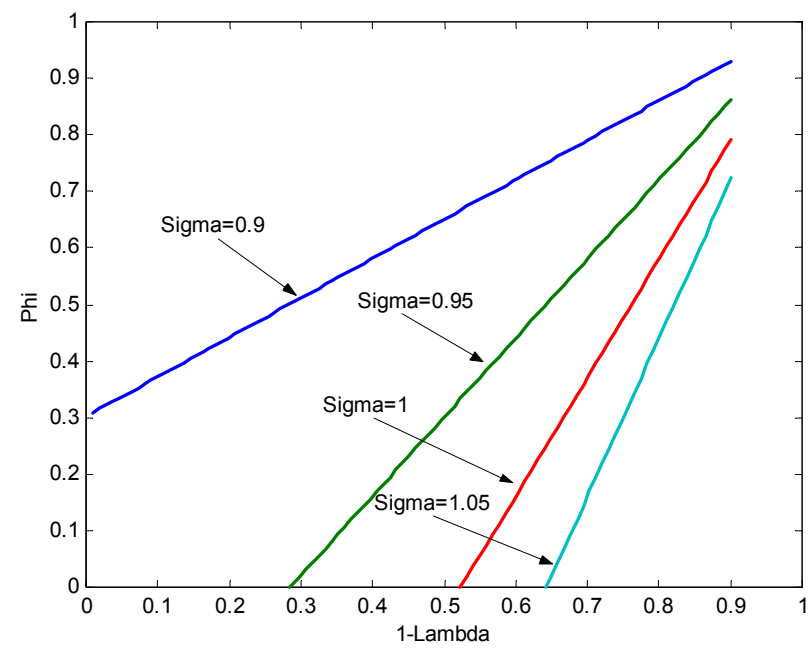

Figure 7: $\phi(1-\lambda)$

Now that we have bounded the R\&D technology using actual US data, we can solve the Social planner's problem to determine the optimal R\&D intensity $\left(s^{*}\right)$.

Her problem can be formalized as follows:

$$
\max _{\left\{c_{t}, R_{t}\right\}} \int_{0}^{\infty} \frac{c_{t}^{1-\theta}-1}{1-\theta} e^{-\varsigma t} d t
$$


subject to:

$$
\begin{aligned}
c_{t} L_{t}+I_{t}+R_{t} & =Y_{t}=A_{t}^{\tilde{\sigma}} Z_{t} K_{t}^{\alpha} L_{t}^{1-\alpha} \\
\dot{K}_{t} & =I_{t}, K_{0}>0 \\
\dot{A}_{t} & =\delta \frac{1}{1+\psi / \psi_{N}} R_{t}^{\lambda} A_{t}^{\phi}, A_{0}>0 \\
\frac{\dot{Z}}{Z} & =\gamma_{Z} ; Z_{0}>0 \\
\frac{\dot{L}}{L} & =n ; L_{0}>0
\end{aligned}
$$

After setting up the Hamiltonian and deriving the first order conditions it is easy to see that in steady state, the social planner devotes a share of output $s^{*}$ to R\&D investments, and this results in a growth rate $\gamma_{A}^{*}$ of $R \& D$-driven technology, where the expressions for these two variables are as follows:

$$
\begin{aligned}
s^{*} & =\tilde{\sigma} \lambda\left[\frac{(1-\phi)}{\lambda}[\theta+\phi-1]+\frac{\varsigma-n(\theta-1)}{\gamma_{A}^{*}}\right]^{-1} \\
\gamma_{A}^{*} & =\frac{(1-\alpha)}{\frac{1-\phi}{\lambda}(1-\alpha)-\tilde{\sigma}}\left[n+\frac{\gamma_{Z}}{1-\alpha}\right]
\end{aligned}
$$

To compute $s^{*}$ I just need to calibrate some parameters that I have not quantified yet. These are $\gamma_{Z}, \varsigma, \theta$. In this model, $Z$ is exogenous. Therefore it is reasonable to assume that $\gamma_{Z}$ is the same in the decentralized and in the planned economy. The production function implies that in steady state, $\gamma_{Z}=(1-\alpha)\left(\gamma_{Y}-n\right)-\tilde{\sigma} \gamma_{A}$.

$\varsigma$ and $\theta$ determine the consumer preferences. The optimal consumption path for the representative consumer in the decentralized economy must satisfy the following Euler equation.

$$
\gamma_{c}=\frac{1}{\theta}[r-n-\varsigma]
$$

The growth rate of the labor force in the US in the post-war period $(n)$ has been equal to 0.0144 and the growth rate of consumption per capita $\left(\gamma_{c}\right)$ has been 0.021 . Therefore if we calibrate the discount rate $(\varsigma)$ to 0.04 , the Euler equation implies an inverse of the elasticity of intertemporal substitution $(\theta)$ between 1 and 2 .

Figure 8 plots the resulting optimal R\&D intensities for several values of $\sigma$ and for the $\lambda^{\prime} s$ that yield a $\phi$ in the interval $[0,1]$. The most striking fact from this figure is that the optimal 
R\&D intensities are not much higher than the actual ones. This finding is robust to alternative parameterizations of $\theta, \varsigma, \sigma$, and of the parameters that determine $\gamma_{A}$.

Kortum [1993] has estimated $\lambda$ to be between 0.1 and 0.6 . Interestingly, for this range of $\lambda$, the actual R\&D intensity roughly coincides with the intensity that the social planner prescribes.

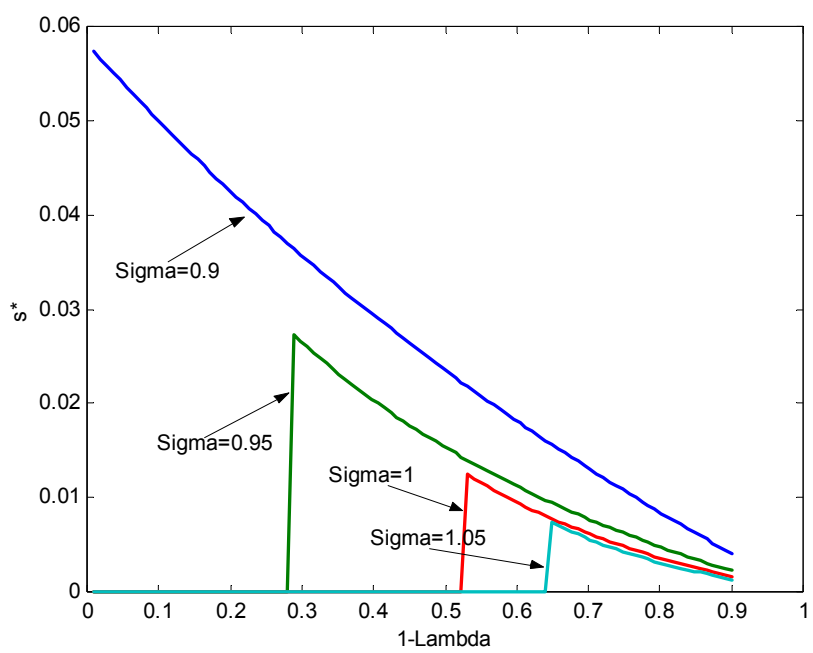

Figure 8: $s^{*}(1-\lambda)$

This conclusion contrasts with Jones and Williams [2000] who find that "the decentralized economy typically underinvests in R\&D relative to what is socially optimal". The reason for the divergence in our findings is that we pursue different strategies to quantify $\gamma_{A}$. While Jones and Williams impose that all TFP growth must be explained by R\&D-driven investments, this paper allows the free entry condition to determine the magnitude of $\gamma_{A}$.

Having said that, it is important to bear in mind that, in contrast to the conclusions of the positive exercise, the validity of this normative conclusion depends on the accuracy of the specification of the production function of new intermediate goods (26) and on the calibration of the degree of aggregate diminishing returns in $\operatorname{R\& D}(\lambda)$.

\section{Where does this leave us?}

Productivity increases because we learn how to use our factors more efficiently. This learning may be a by-product of other activities not directed at increasing the productivity of resources or the result of investment efforts directed towards the improvement of productivity. In this paper I have focused in evaluating the contribution to productivity growth of one of these investments, R\&D. 
From the free entry condition into $R \& D$ and the fact that $R \& D$ innovations are embodied in the sense of Solow [1959], I have shown that the notion of R\&D measured by the NSF is not responsible for a large share of productivity growth in the US. Since the US is the world leader in R\&D, this conclusion can be made extensive to the other nations.

Our prior was that $R \& D$ is the main source of long run growth. The immediate question that emerges from this analysis is "then, what is the driving force of productivity growth?". This question should be placed at the top of the research agenda.

I would like to stress that the relatively minor contribution of $R \& D$ to productivity growth found in this analysis does not imply in any way that other purposeful investments (on management, organization, personnel, financial engineering, and many other areas) directed to improve productivity are not very important. There are indeed two reasons to anticipate an important contribution from these non-R\&D investments. First, the size of the expenditures in these other activities is probably one order of magnitude larger than $R \& D$ expenditures. Second, since the innovations that result from these investments are disembodied, not patentable and quite easy to imitate, the externalities associated with them are probably much larger.

From a normative perspective, the analysis conducted in this paper implies that the decentralized economy may not be underinvesting in $\mathrm{R} \& \mathrm{D}$. 


\section{References}

[1] Aghion, P. and P. Howitt [1992], "A Model of Growth Trough Creative Destruction" Econometrica, 60,2 (March), 323-351.

[2] Barro, R. and X. Sala-i-Martin [1995] Economic Growth McGraw Hill, New York.

[3] Basu, S. [1996] "Procyclical Productivity: Increasing Returns or Cyclical Utilization?" Quarterly Journal of Economics 111, 709-751.

[4] Caballero, R. and A. Jaffe [1993], "How High are the Giants' Shoulders?" In O. Blanchard and S. Fisher (eds.), NBER Macroeconomics Annual. Cambridge, MA: MIT Press.

[5] Campbell, J. and P. Perron [1991], "Pitfalls and Opportunities: What Macroeconomists Should Know about Unit Roots" In O. Blanchard and S. Fisher (eds.), NBER Macroeconomics Annual. Cambridge, MA: MIT Press.

[6] Comin, D. [2002], "R\&D? A Small Contribution to Productivity Growth", C.V. Starr wp \# 2002-01

[7] Fisher, F., D. Levhari, E. Sheshinski [1969]. "On the Sensitivity of the Level of Output to Savings: A Clarification Note", Quarterly Journal of Economics, 83(2), 347-348.

[8] Griliches, Z. [1992], "The Search for R\&D Spillovers" Scandinavian Journal of Economics $94,29-47$.

[9] Grossman, G. and E. Helpman [1991], Innovation and Growth in the Global Economy, Cambridge, MA: MIT Press.

[10] Hamilton, J. [1994] Time Series Analysis Princeton University Press. Princeton, NJ.

[11] Herrera, H. and E. Schroth [2002] "Profitable Innovation Without Patent Protection: The case of Credit Derivatives" NYU mimeo.

[12] Jones, C. [2002] "Sources of U.S. Economic Growth in a World of Ideas" American Economic Review.92,1, pp. 220-239.

[13] Jones, C. and J. Williams [1998] "Measuring the Social Return to R\&D" Quarterly Journal of Economics 113, 1119-1138. 
[14] Jones, C. and J. Williams [2000] "Too Much of a Good Thing? The Economics of Investment in R\&D" Journal of Economic Growth, 5:65-85.

[15] Kortum, S [1993] "Equilibrium R\&D and the patent-R\&D Ratio: U.S. Evidence" American Economic Review, 83, 450-457.

[16] Levhari, D. and E. Sheshinski [1969]. "On the Sensitivity of the Level of Output to Savings", Quarterly Journal of Economics, 81, 524-528.

[17] Mansfield, E., M. Schwartz and S. Wagner [1981] "Imitation Costs and Patents: An Empirical Study" Economic Journal 91, 907-918.

[18] Matthews, R. [1964]. "The New View of Investment: Comment", Quarterly Journal of Economics, 78(1), 164-172.

[19] McHugh R. and J. Lane [1987]. " The Role of Emdodied Technological Change in the Decline of Labor Productivity" Southern Economic Journal Vol. 53 (4), p. 915-24.

[20] Mehra, R. and E. Prescott [1985] "The Equity Premium: A Puzzle" Journal of Monetary Economics 15, 145-161.

[21] Nadiri, I. [1993], "Innovations and Technological Spillovers" C.V. Starr Working paper \#9331.

[22] Norrbin, S. [1993] "The Relationship between Price and Marginal Cost in U.S. Industry: A Contradiction" Journal of Political Economy 101, 1149-1164.

[23] Phelps, E. [1962]. "The New View of Investment: A Neoclassical Analysis", Quarterly Journal of Economics, 76(4), 548-567.

[24] Phelps, E. and M. Yaari [1964]. "The New View of Investment: Reply", Quarterly Journal of Economics, 78(1), 172-176.

[25] Pakes, A. and M. Schankerman [1984] "The Rate of Obsolescence of Patents, Research Gestation Lags and the Private Rate of Return to Research Resources." In Zvi Griliches (ed.), Patents and Productivity .Chicago: University of Chicago Press. 
[26] Rapoport, J. [1971] The Autonomy of the Product-innovation Process: Cost and Time. In Research and Innovation in the Modern Corporation, ed. E. Mansfield, 110-35. New York: Norton.

[27] Romer, P. [1990] "Endogenous Technological Change" Journal of Political Economy 98, S71-S102.

[28] Solow, R. [1959] "Investment and Technical Change" in Mathematical Methods in the Social Sciences, Stanford.

[29] Stokey, N [1995] "R\&D and Economic Growth" Review of Economic Studies 62, 469-489.

[30] Wagner, L. [1968] Problems in estimating research and development investment and stock. In Proceedings of the business and economic statistics section, 189-98. Washington, D.C.: American Statistics Association. 


\section{Appendix}

In this appendix I extend the baseline model to accommodate dynamic increasing returns into $R \& D$ by allowing firms to have a subsequent $R \& D$ advantage. Then, I use this extension to show that the $R \& D$ contribution to productivity growth is lower when firms have a subsequent $R \& D$ cost advantage than in the baseline case.

Let's suppose that an incumbent firm $j$ with $i>0$ active innovation clusters has the ability to develop up to $i$ new innovation clusters every instant. Let $r_{i j}$ denote the amount of $\mathrm{R} \& \mathrm{D}$ this firm conducts for each of the $i$ projects. Success at each of the projects arrives with an independent Poisson rate $\delta\left(r_{i j},\left\{R_{c}\right\}_{c=1}^{\infty},\left\{A_{c}\right\}_{c=1}^{\infty}\right)$, where $R_{i}$ and $A_{i}$ denote respectively the total $R \& D$ investments and the total number of varieties available in the market from the firms with exactly $i-1$ active clusters. The only restrictions I impose on $\delta$ are that it is increasing and concave in $r_{i j}$. Let $N_{i-1}$ be the number of firms with exactly $i-1$ active technological clusters. The framework described so far implies that the total number of clusters developed every instant by firms with already $i-1 \geq 0$ active technological clusters is

$$
\frac{\dot{A}_{i}}{\psi_{N}}=N_{i-1} i \delta\left(r_{i j},\left\{R_{c}\right\}_{c=1}^{\infty},\left\{A_{c}\right\}_{c=1}^{\infty}\right) .
$$

One important modification introduced with this setup is that the firm now internalizes part of the intertemporal consequences of its $R \& D$ investments because it is aware that succeeding in developing the next technological cluster increases the chances of developing new clusters in the future. However, for simplicity, I still assume that the number of firms in each size group $\left(N_{i}\right)$ is large and therefore that the effects of $r_{i j}$ on $R_{i}$, and of $A_{i j}$ on $A_{i}$ are negligible. ${ }^{26}$ This means that incumbents select $r_{i j}$ to maximize $i\left[\delta\left(r_{i j},\left\{R_{c}\right\}_{c=1}^{\infty},\left\{A_{c}\right\}_{c=1}^{\infty}\right)\left(V_{i+1}-V_{i}\right)-r_{i j}\right]$ taking as given $\left\{R_{c}\right\}_{c=1}^{\infty}$ and $\left\{A_{c}\right\}_{c=1}^{\infty}$.

The optimal level of $r_{i j}$ (denoted by $r^{*}$ ) does not depend directly on $i$, and satisfies the following first order condition:

$$
\frac{\partial \delta\left(r^{*},\left\{R_{c}\right\}_{c=1}^{\infty},\left\{A_{c}\right\}_{c=1}^{\infty}\right)}{\partial r_{i j}}\left(V_{i+1}-V_{i}\right)=1, \text { for } i>0
$$

From this framework, it follows that

$$
\frac{1}{R_{i}} \frac{\dot{A}_{i}}{\psi_{N}}=\frac{\delta\left(r^{*},\left\{R_{c}\right\}_{c=1}^{\infty},\left\{A_{c}\right\}_{c=1}^{\infty}\right)}{r^{*}}>\frac{\partial \delta\left(r^{*},\left\{R_{c}\right\}_{c=1}^{\infty},\left\{A_{c}\right\}_{c=1}^{\infty}\right)}{\partial r_{i j}}=\frac{1}{V_{i+1}-V_{i}}, \text { for } i>0
$$

\footnotetext{
${ }^{26}$ This seems to me the most reasonable scenario: one where firms internalize the cost advantage of subsequent innovation but do not internalize the aggregate diminishing returns to R\&D or the aggregate intertemporal externalities.
} 
where the first equality comes from the production function for $R \& D$ (30), the inequality is a consequence of the concavity of $\delta$ on $r_{i j}$, and the second equality follows from the first order condition (31). Rewriting this, we observe that incumbent R\&D firms make positive profits on average from successive innovations.

$$
\left(V_{i+1}-V_{i}\right) \frac{\dot{A}_{i}}{\psi_{N}}>R_{i}
$$

For new R\&D firms, however, free entry brings down the expected value of a firm with exactly one cluster to the cost of developing the first innovation cluster.

$$
V_{1} \frac{\dot{A}_{1}}{\psi_{N}}=R_{1}
$$

As before, we can derive the relationship between $s$ and $\gamma_{A}$ by pricing the R\&D firms. The value of a firm with exactly $i \geq 1$ active clusters satisfies the following asset equation:

$$
r V_{i}=i \pi\left(\psi+\psi_{N}\right)+\dot{V}_{i}-i \frac{\dot{A}}{\psi_{N}} \frac{\left(\psi+\psi_{N}\right)}{A}\left(V_{i}-V_{i-1}\right)+i \max _{r_{i}} \delta\left(r_{i},\left\{R_{c}\right\}_{c=1}^{\infty},\left\{A_{c}\right\}_{c=1}^{\infty}\right)\left(V_{i+1}-V_{i}\right)-r_{i}
$$

Using the definition of $r^{*}$ and dividing by $V_{i}$, we obtain:

$r=i \frac{\pi}{V_{i}}\left(\psi+\psi_{N}\right)+\frac{\dot{V}_{i}}{V_{i}}-i \frac{\dot{A}}{\psi_{N}} \frac{\left(\psi+\psi_{N}\right)}{A}\left(\frac{V_{i}-V_{i-1}}{V_{i}}\right)+i \delta\left(r^{*},\left\{R_{c}\right\}_{c=1}^{\infty},\left\{A_{c}\right\}_{c=1}^{\infty}\right)\left(\frac{V_{i+1}-V_{i}}{V_{i}}\right)-i \frac{r^{*}}{V_{i}}$

At this point, we can make a very useful observation. If $V_{i}=i V_{1}$, the RHS of this equation is independent of $i$. This means that we can find a solution to this system of difference equations by just solving the one for $V_{1}$. Using this shortcut we can reduce the system to:

$$
r=\frac{\pi}{V_{1}}\left(\psi+\psi_{N}\right)+\frac{\dot{V}_{1}}{V_{1}}-\frac{\dot{A}}{\psi_{N}} \frac{\left(\psi+\psi_{N}\right)}{A}+\overbrace{\delta\left(r^{*},\left\{R_{i}\right\}_{i=1}^{\infty},\left\{A_{i}\right\}_{i=1}^{\infty}\right)-\frac{r^{*}}{V_{1}}}^{\text {profit rate from subsequent R\&D }}
$$

The free entry condition for new innovators (33) implies that:

$$
V_{1}=\frac{s_{1} \psi_{N}}{\frac{\dot{A}_{1}}{A_{1}} \frac{A_{1}}{A}} \frac{Y}{A}
$$

where $s_{1}$ is the share of R\&D conducted by entrants in total output. Since in the steady state $\gamma_{A_{1}}$, $s_{1}$ and $\frac{A_{1}}{A}$ are constant, $\gamma_{V_{1}}=\gamma_{Y}-\gamma_{A}$. 
From (33) and (32) it follows that

$$
\begin{aligned}
\sum_{i=1}^{\infty}\left(V_{i}-V_{i-1}\right) \frac{\dot{A}_{i}}{\psi_{N}} & >\sum_{i=1}^{\infty} R_{i} \\
V_{1} \frac{\dot{A}}{\psi_{N}} & >R \\
V_{1} & >\frac{s \psi_{N}}{\gamma_{A}} \frac{Y}{A},
\end{aligned}
$$

where the second inequality takes advantage of the fact that $V_{i}=i V_{1}$.

Plugging (35) into the asset equation (34) we obtain the following inequality:

$$
r>\frac{\left(\frac{\eta-1}{\eta}\right) \alpha\left(\psi+\psi_{N}\right)}{s \psi_{N}} \gamma_{A}+\gamma_{Y}-\gamma_{A}-\frac{\left(\psi+\psi_{N}\right)}{\psi_{N}} \gamma_{A}+\overbrace{\delta\left(r^{*},\left\{R_{i}\right\}_{i=1}^{\infty},\left\{A_{i}\right\}_{i=1}^{\infty}\right)-\frac{r^{*}}{V_{1}}}^{>0}
$$

And from here,

$$
\gamma_{A}<\frac{r-\gamma_{Y}-\overbrace{\left(\delta\left(r^{*},\left\{R_{i}\right\}_{i=1}^{\infty},\left\{A_{i}\right\}_{i=1}^{\infty}\right)-\frac{r^{*}}{V_{1}}\right)}^{>0}}{\frac{\left(\frac{\eta-1}{\eta}\right) \alpha e^{-\left(r-g_{Y}\right) l}}{s}\left(1+\frac{\psi}{\psi_{N}}\right)-\left(2+\frac{\psi}{\psi_{N}}\right)}
$$

To relate this expression with the growth rate of varieties when innovators are small (??), recall that incumbents make positive profits from subsequent R\&D. This means that the new term in the numerator is strictly positive and that instead of an equality, now we have an strict inequality. As a result, the $\gamma_{A}$ implied by $s$ when we allow firms to partially internalize the future cost advantages of their current R\&D (i.e. when they are large) is lower than when they are small. 